\title{
Asset Mapping as a Research Tool for Community-Based Participatory Research in Social
}

\author{
Work \\ Elizabeth Lightfoot ${ }^{\mathrm{a}}$, Jennifer Simmelink McCleary ${ }^{\mathrm{b}}$, Terry Lum $^{\mathrm{c}}$ \\ ${ }^{a}$ School of Social Work, University of Minnesota, St. Paul, MN, USA \\ ${ }^{b}$ School of Social Work, University of Minnesota, St. Paul, MN, USA \\ ${ }^{c}$ School of Social Work, University of Hong Kong, Hong Kong
}

This is an Accepted Manuscript of an article published by Oxford University Press in Social Work Research in March, 2014, available online: https://dx.doi.org/10.1093/swr/svu001

It is deposited under the terms of the Creative Commons Attribution-NonCommercialNoDerivatives License (http://creativecommons.org/licenses/by-nc-nd/4.0/), which permits noncommercial re-use, distribution, and reproduction in any medium, provided the original work is properly cited, and is not altered, transformed, or built upon in any way. 


\begin{abstract}
Participatory research approaches such as community-based participatory research (CBPR) have emerged as an innovative way of conducting social work research. As social work researchers increasingly incorporate participatory approaches, they adopt and adapt research methods and procedures to fit participatory models. One such procedure, asset mapping, provides an appropriate method for conducting research and is particularly well suited to both the CBPR approach and social work's strengths-based approach to social issues. Although asset mapping as a community practice technique is not new to social work, it has been seldom used as a research tool in social work research and is generally not introduced as a research method in social work courses or in social work research textbooks.
\end{abstract}

\title{
Origins and Overview of Asset Mapping
}

Asset mapping is a method of research originally developed as part of Kretzmann and McKnight's (1993) asset-based community development (ABCD) strategy for community building and community capacity building. In the ABCD approach, a community explores, describes, and maps its assets and then uses these assets to develop solutions to a specific social issue within the community, such as homelessness, hunger, access to health care, or poverty. This approach shares commonalities with one of the dominant models in social work behavioral intervention, the strengths-based approach, that seeks to build on the strengths of individuals and families (Saleebey, 1992). Similar to the strengths perspective, the asset approach to community development emphasizes the positive ability, capability, and capacity of communities to identify relevant issues; to develop appropriate solutions from the strengths of their community members, institutions, and structures; and to implement such solutions in a culturally appropriate, 
sustainable way. The asset approach differs from the more prominent deficit orientation to community development, which has historically focused on problems or risks of local communities that require professional resources and interventions (Morgan \& Ziglio, 2007).

In the typical $\mathrm{ABCD}$ process, communities map assets, evaluate asset data, mobilize assets for development, and then assess development efforts and the strength of connections. Although the processes of ABCD can vary, its key components are its focus on assets rather than deficits and its participatory approach. The assets in the ABCD approach include both tangible assets, such as a church congregation, a playground, or a community organization, and intangible assets, such as cultural traditions or social support networks. Assets include the skills and capacities of individuals; informal and formal associations, such as local card-playing or religious groups, sports clubs, or service organizations; institutions, such as hospitals, clinics, neighborhood centers, or libraries; economic development potential; and land and other physical assets (Kretzmann \& McKnight, 1993).

Asset mapping is the process by which the community identifies individual, associational, institutional, economic, physical, and cultural assets. This process involves community members in defining the boundary of a community, exploring and identifying community assets, conducting an inventory of the community assets, and composing a physical and/or conceptual map of the community's assets that also highlights the interconnections and relationships among the assets. This in turn leads to community interventions that build directly on the assets in the community.

Community members, organizations within the community, and others can use the asset map to strengthen assets that are already present, to develop new assets where they are needed, and to strengthen connections between various assets. The assets-based model enhances the 
capacities of individuals and communities to realize their potential to contribute to their own development and strengthens the communities' ownership of that development. Asset mapping has typically been used as a step in community development or organizing, often from a grassroots participatory action research perspective, in which the community is interested in gaining knowledge for its own concerns. Participation in the mapping process can become an intervention, as it builds trust among community members, develops the capacities of the asset mappers, and engenders a sense of community pride. Asset mapping as a community development or organizing technique produces a community asset inventory or asset map that community stakeholders can use to solve their community problems and to promote community development.

The World Health Organization (WHO) has recognized that assets-based approaches to health promotion are critical for supporting overall population health and reducing health disparities (Harrison, Ziglio, Levin, \& Morgan, 2004). Health assets approaches were used by the American Academy of Pediatrics Community Access to Child Health to help pediatricians work with local associations (McKnight \& Pandak, 1999); a large international consortium, the African Religious Health Assets Program, was funded by the WHO to conduct extensive assetmapping research in Africa (African Religious Health Assets Program, 2006). Assets approaches have been used to develop a variety of health promotion activities, such as reducing television viewing (Baker et al., 2007) and tobacco use (Struthers, Hodge, Geishirt-Cantrell, \& Casken, 2003).

Asset-mapping approaches to community development in the field of social work range from surveying communities to developing a list of resources (Ulrich, Soska, \& Richter, 2005), to establishing international community development projects that leverage identified assets to 
create new interventions and close resource gaps (Ssewamala, Sperber, Zimmerman, \& Karimli, 2010). Many community practice social work textbooks advocate asset mapping as a community development strategy (Hardcastle, Powers, \& Wenocur, 2011; Weil, 2004). Social work researchers have begun to build an evidence base to support asset mapping as an intervention tool in community development and macro practice with communities.

\section{Asset Mapping As a Research Technique}

Whereas asset mapping was designed as a community development technique and is well known as such within the field of social work practice, it can also be used as a research technique. A review of the social work literature reveals that only a handful of studies use asset mapping as a research technique. Asset mapping as a research technique produces valid and reliable data that help researchers and stakeholders understand the strengths of a community and its ability to solve its problems. The research data generated from asset mapping, such as asset inventories or asset maps, can be used as dependent or independent variables in the research process. Asset mapping is not necessarily participatory, as a research team could hire its own asset mappers. However, a participatory approach in asset mapping increases the validity of the asset inventory and asset map produced, particularly if the researchers are not members of the community being studied. A participatory approach also allows social work researchers to develop strong partnerships with communities.

Asset mapping is increasingly being used as a research tool as participatory research methods such as CBPR have gained prominence in social work and health research. CBPR is a participatory method that arose in the field of public health research. CBPR was developed as a way to encourage partnerships between academic researchers and communities; to develop 
appropriate, rigorous research methods that lead to valid findings; and to translate research findings into relevant practice and policy changes. Israel and colleagues (Israel, Eng, Schulz, Parker, \& Satcher, 2005) described CBPR as being fundamentally about equitable partnerships, where researchers and community partners share responsibility throughout a research project. A CBPR approach to research can involve either quantitative or qualitative methods and emphasizes collaboration, shared power, and ownership over the research process and resulting data and long-term connections between researchers and communities. Generally, CBPR research includes the translation of research findings into policy and practice changes within the same community. Asset mapping is an ideal participatory method for use within the CBPR approach to research.

Social work researchers frequently strive to develop community-university partnerships through their research, and these partnerships are an essential component of participatory research approaches. Asset mapping allows social work researchers to begin to develop longterm and committed partnerships with community members from a strengths-based perspective. Participatory asset mapping requires researchers and community members to work, to communicate, to compromise, to learn about each other's strengths and weaknesses, and to create together. These elements are building blocks to successful community-university partnerships.

\section{Method of Asset Mapping in CBPR}

The technique of mapping communities has been used in public health for many years, and it usually originates from a deficit-based or problem framework to map out such factors as health risks (Ayala, Maty, Cravey, \& Webb, 2005). Community mapping typically uses spatial data to learn about communities. Asset mapping differs from traditional mapping of communities 
in its focus on assets rather than deficits and its use of community members in the identification, collection, and analysis of assets. Key methodological issues in asset mapping in CBPR include identifying the research question, defining the boundaries of the community, identifying the types of assets that will be inventoried and mapped, mapping those assets, and creating a valid and reliable asset inventory and asset map. In CBPR, this is a collaborative process between the community and the researchers. The community and researchers jointly identify the boundary of the community. It can be physical, such as a city block, or nonphysical, such as an ethnic or cultural group. The community and researchers jointly own the research question. Some of the sophisticated mapping techniques that have been developed in the fields of geography or urban affairs, such as using global positioning system (GPS) software technologies and geographic information systems (GIS) for locating, managing, analyzing, and presenting assets, can be easily integrated into asset mapping through mobile phones or tablet computers.

Data collection in asset mapping can be qualitative or quantitative. Data about tangible assets are collected with methodologies most similar to traditional community mapping, such as asset inventories designed to measure the particular type of asset under investigationindividual, associational, or institutional. The asset inventories can be conducted through mail or online surveys, structured interviews, or focus groups and community meetings. For example, community members can collect information on individual assets through structured interviews using structured interview guides called individual asset inventories. These inventories can be designed to measure particular individual-level skills or capacities. Likewise, structured interviews can be used to collect data to complete associational asset inventories or organizational asset inventories. For some types of tangible assets, resource inventories can be conducted through observations, with the community members observing such data as the 
number of playgrounds or grocery stores in a neighborhood. For all types of tangible assets, maps can be created using low- or high-technology methods. In community development, lowtechnology methods of creating maps have used community members to directly mark on existing street or physical maps the location of various types of resources. GIS can be used to create maps of these assets that can be more easily analyzed. The findings from the mapping of tangible assets can be used to answer all sorts of research questions, such as the relationships among various types of assets or the relationships between assets and other variables. Likewise, the mapping of tangible assets can be useful for developing appropriate interventions. The development of an asset map as a community-level intervention can also be evaluated.

Data about intangible assets, such as some types of associational assets or cultural assets, are often collected through interviews or focus groups with key stakeholders and/or local community members. The data collected are usually qualitative data, which must be analyzed to ascertain the key assets under question. Adhering to the CBPR influence of asset mapping, qualitative researchers and community experts often work together to conduct this analysis. This process might be tedious, but it is advantageous in that it draws on the data analysis expertise of the researchers and the community expertise of the community members. Another approach for determining key assets is to hold community meetings or forums to present the qualitative data and then have the community members determine the key assets through voting techniques, such as the nominal group technique that uses small group discussions and prioritization to reach group consensus.

This asset-mapping process, even when used as a research tool instead of explicitly as an organizing tool, mobilizes a community to use its assets to develop its interventions, which fits neatly with the CBPR approach. Indeed, the main tenets of the asset approach are congruous 
with the nine principles of CBPR (Israel et al., 2005). Both CBPR and the assets-mapping process view the community as a key player, facilitate collaborative partnerships, foster colearning and capacity building among all partners, view health from an ecological approach, balance knowledge generation with intervention, and aim for long-term sustainability. The assets model views the community as both a coproducer of knowledge and a coproducer of health, rather than just a participant in research or a consumer of health (Morgan \& Ziglio, 2007). It is a positive, realistic approach to building the strengths of local communities toward health improvements and provides a starting point for taking action in a way that builds trust between professionals and local communities. Asset mapping allows communities to self-identify real assets and their characteristics, leading to a more realistic portrayal of and plan for building on those strengths.

The quality of data that are collected through asset-mapping can be equal to or better than that from traditional collection methods, such as survey or focus group interviews. In CBPR, data collected through asset mapping can have a higher validity than data from traditional methods, as all stakeholders are involved in the selection of assets to be mapped and the methods for mapping. However, if asset mapping is used in a non-CBPR research, the validity of the data could be very similar to that of data collected using other methods. The reliability of the assetmapping data depends on the nature of the asset being mapped and the training of the asset mappers. For tangible assets, such as physical infrastructure, the reliability can be very high, particularly in CBPR as both researcher and community participants contribute to identifying the best asset-mapping methods. For intangible assets, such as relationships or cultural practice, the reliability of data can be improved through adequate training of asset mappers, detailed 
instructions for the asset-mapping process, and the determination that a high level of intermapper reliability has been achieved before the actual asset mapping is begun.

\section{Asset Mapping in Social Work Research}

Asset-based approaches are commonplace in community development efforts; but asset mapping is rarely used by social work researchers, despite the discipline's long-standing embrace of the $\mathrm{ABCD}$ as a social work practice model and its integration into social work education. The use of asset mapping as a research tool is currently most prominent in health disparities research. Corbie-Smith et al. (2010) successfully incorporated asset mapping into a CBPR project to develop church-based HIV/AIDS interventions. Social capital and social network theory are frequently incorporated into studies using asset mapping as a research or intervention strategy (Boyd, Hayes, Wilson, \& Bearsley-Smith, 2008; Ennis \& West, 2010). Butterfield, Kebede, and Gessesse (2009) used asset mapping in a study on slum housing and income generation in Addis Ababa, Ethiopia, to assess the skills and capacities of a random sample of poor women. Their findings led to the incorporation of social network analysis into a future study to better understand and support the income-generating networks of women (Kebede \& Butterfield, 2009). Lo (2008) used an asset-based approach to analyze the efficacy of partnerships among international development agencies, governments, and communities that deliver maternal and child health care in Senegal and Mali. Similarly, Lightfoot (2011) describes a social work CBPR study that used $\mathrm{ABCD}$ to determine the cultural health assets of East African residents living in a midwestern city in the United States. In this study, community asset mappers were involved in surveying community members regarding their cultural health assets, 
and the findings from this research project were used in developing community health interventions.

There are challenges to using asset mapping as a research tool, similar to the general challenges of using a CBPR approach. Asset mapping is time intensive and requires an extensive amount of training and oversight. Likewise, the community-university partnership must be maintained throughout the process. Some researchers have found that there can be challenges related to the implementation of findings. Amsden and VanWynsberghe (2005) found that asset mapping was a useful tool for engaging youth in an evaluation of health clinics. However, even though asset mapping was an effective way to get youth engaged in the project, acting on the findings was challenging. Conversely, El-Askari, Freestone, Irizarry, Kraut, and Mashiyama (1998) found that residents of a public housing complex were empowered to take on additional, successful health actions after the completion of a project involving asset mapping. Social work researchers have been leaders in adopting asset mapping as both a community intervention tool and a research tool, although its use is still relatively limited.

\section{Future Directions}

Asset mapping is well suited for social work practice with communities and as a research method for use in social work CBPR research partnerships that explore social issues. Asset mapping can help tease out the strengths of communities, which is of interest to both social work researchers for developing the social work knowledge base and community stakeholders interested in developing culturally appropriate programs, models, or interventions. Asset mapping fits well with social work's strengths-based approach to conducting research in lowresource communities. It emphasizes the strengths that communities possess and allows them to 
discover untapped resources and strengths. Furthermore, asset mapping is a fairly straightforward approach, which has grown out of a community practice intervention that is well known among community organizers. As CBPR research requires community members and research participants to be an integral part of developing research questions, choosing research methodologies, and implementing the study design, asset mapping is a method that has appeal to community partners. Many community members lack highly specialized training in complex research methodologies that involve lengthy surveys or complex statistical analysis. For this reason, CBPR studies have traditionally relied on qualitative research methodologies that are rigorous but easily implemented by nonresearchers. Asset mapping allows for quantitative analysis of assets in an easily understood and implemented format. Finally, asset mapping has been used in social work as an intervention, and the evidence base for ABCD projects is robust. However, few social work researchers have used asset mapping or asset-based strategies as a tool to conduct the research itself. As the field of social work research is increasingly using the CBPR approach for research and is concerning itself with developing culturally appropriate interventions, more social work researchers may consider integrating asset-mapping methods in their CBPR projects.

\section{References}

African Religious Health Assets Program. (2006) Appreciating assets: The contribution of religion to universal access in Africa, Geneva, World Health Organization

Amsden J., VanWynsberghe R. (2005). Community mapping as a research tool with youth, Action Research, 3, 357-381. 
Ayala G. X., Maty S., Cravey A., Webb L., Israel B. A., Eng E., Schulz A. J., Parker E. A., \& Satcher D. (2005). Mapping social and environmental influences on health: A community perspective, Methods in conducting community-based participatory research for health. San Francisco. Jossey-Bass, pgs. 188-209.

Baker I., Dennison B., Boyer P., Sellers K., Russo T., \& Sherwood N. (2007). An asset-based community initiative to reduce television viewing in New York state. Preventive Medicine, 44, 437-441

Boyd C. P., Hayes L., Wilson R. L., \& Bearsley-Smith C. (2008). Harnessing the social capital of rural communities for youth mental health: An asset-based community development framework. Australian Journal of Rural Health, 16(4), 189-193.

Butterfield A., Kebede W., \& Gessesse A. (2009). Research as a catalyst for asset-based community development: Assessing the skills of poor women in Ethiopia. Social Development Issues, 31(2), 1-14.

Corbie-Smith G., Akers A., Blumenthal C., Council B., Wynn M., Muhammad M., \& Stith, D. (2010). Intervention mapping as a participatory approach to developing an HIV prevention intervention in rural African American communities. AIDS Education and Prevention, 22(3), 184-202. 
El-Askari G., Freestone J., Irizarry C., Kraut K. L., Mashiyama S. T. (1998). The Healthy Neighborhoods Project: A local health department's role in catalyzing community development. Health Education Behavior, 25, 146-159.

Ennis G. \& West D. (2010). Exploring the potential of social network analysis in asset based community development. Australian Social Work, 63, 404-417.

Hardcastle D. A., Powers P. R., \& Wenocur, S. (2011). Community practice: Theories and skills for social workers. England. Oxford University Press.

Harrison D., Ziglio E., Levin L., \& Morgan A. (2004). Assets for health and development: Developing a conceptual framework. Venice, Italy. Office for Investment for Health and Development, World Health Organization.

Israel B., Eng E., Schulz A., Parker E., \& Satcher D. (2005). Methods in community-based participatory research for health, San Francisco. Jossey-Bass.

Kebede W., Butterfield A. K. (2009). Social networks among poor women in Ethiopia. International Social Work, 52, 357-374.

Kretzmann J., McKnight J. (1993). Building communities from the inside out: A path toward finding and mobilizing a community's assets, Evanston, IL. Institute for Policy Research. 
Lightfoot E. (2011). Cultural health assets of East African immigrant communities in the Cedar Riverside neighborhood. Minneapolis. Brian Coyle Center.

Lo M. (2008). Public-private partnerships for maternal health in Africa: Challenges and prospects, Marriage \& Family Review, 44(2-3), 214-237.

McKnight J. \& Pandak C. (1999). New community tools for improving child health: A pediatrician's guide to local associations. Elk Grove Village, IL. American Academy of Pediatrics.

Morgan A. \& Ziglio E. (2007). Revitalising the evidence base for public health: An assets model, Global Health Promotion, 14(2), 17-22.

Saleebey D. (1992). The strengths perspective in social work practice. New York. Longman.

Ssewamala F. M., Sperber E., Zimmerman J. M., \& Karimli L. (2003). The potential of assetbased development strategies for poverty alleviation in sub-Saharan Africa. International Journal of Social Welfare, 19, 433-443.

Struthers R., Hodge F., Geishirt-Cantrell B., Casken J. (2003). Community mapping: A tool in the fight against cigarette smoking on American Indian reservations. Policy Politics \& Nursing Practice, 4, 295-302. 
Ulrich C., Soska T. M., \& Richter J. (2005). Hazelwood community asset map: Assessing the services, needs and strengths of Hazelwood's community service providers. Pittsburgh. University of Pittsburgh Community Outreach Partnership Center.

Weil M. (2004). The handbook of community practice. Thousand Oaks, CA. Sage Publications. 